\title{
ATUALIZAÇÃO NA ASSISTÊNCIA PRÉ-NATAL BASEADA EM EVIDÊNCIA E CENTRADA NO PACIENTE
}

\author{
Victor Hugo de Melo, Wanderley Marques Bernardo
}

\section{TEMAABORDADO}

Especialidade de abrangência: Ginecologia e Obstetrícia.

Diretriz a ser consultada: Assistência pré-natal - partel.

CenáRIOS e QUeSTÓ̃es CLÍNICAS

I. Os resultados falsos-positivos no diagnóstico precoce da gravidez pela dosagem da gonadotrofina coriônica humana (BhCG) ocorrem na faixa:
a. 25 a $30 \mathrm{mUl} / \mathrm{ml}$
b. 2 a $25 \mathrm{mUl} / \mathrm{ml}$
c. Acima de $25 \mathrm{mUI} / \mathrm{ml}$
d. Menor que $5 \mathrm{mUI} / \mathrm{ml}$
e. Não há falsos-positivos

2. Com relação a situações gerais que produzem benefício ou risco à gravidez podemos afirmar que:

a. A suplementação dietética com fibras vegetais ajuda a reduzir a constipação

b. Banho quente de hidromassagem não se associa a risco maior de abortamento antes da 20a semana

c. Orepouso no leito, domiciliar ou hospitalar, previne o parto pré-termo

d. Viagens aéreas não são seguras para a grávida até I 2 semanas antes da data provável do parto

e. Os riscos e benefícios do exercício aeróbico para a mãe e o recém-nascido já estão bem estabelecidos

\section{As gestantes que trabalham têm maior risco de aborto espontâneo, quando:}

a. Têm antecedente de abortamento, independente da atividade

b. Mesmo quando não têm antecedente de abortamento, independente da atividade

c. Têm antecedente de abortamento e trabalham mais de sete horas em pé

d. Sem antecedente de abortamento, e que trabalham em pé mais de 12 horas

e. Não há situações relacionadas ao trabalho que aumentam o risco de abortamento

\section{4. É incorreto afirmar, em relação à ingestão de álcool durante a gestação, que:}
a. A ingestão de sete ou mais doses de bebida alcoólica por semana aumenta o risco de lesões cerebrais em RN prematuros
b. Aabstinência é o recomendado
c. Não há vantagens de visitação domiciliar de equipe multidisciplinar a gestante com problemas de abuso de álcool
d. Recomenda-se a ingestão no máximo de até sete doses de álcool por semana
e. Os programas de aconselhamento podem ser úteis para a diminuição do consumo de álcool das gestantes

\section{A atividade sexual no terceiro trimestre da gravidez:}
a. Deve ser evitada
b. Está associada a aumento na mortalidade perinatal
c. Está associada a aumento da prematuridade
d. Depende da presença de vaginose ou tricomoníase
e. Não apresenta aumento de risco para o feto

\section{Respostas do Cenário Clínico: AtualizaÇÃo no tratamento dos tumores Congênitos de Pescoço, BASEAdA em eVIDên-} CIA E CENTRADA NO PACIENTE. [PUBLICADO NA RAMB 2007; 53(5)]

I. Os linfangiomas podem ser classificados em simples, cavernoso ou higroma cístico. As diferenças dizem respeito à espessura da adventícia e tamanho dos espaços vasculares (Alternativa A).

2. Otratamento dos linfangiomas pode ter como opções, exceto a radioterapia (Alternativa D).

3. Otratamento das anomalias dos arcos branquiais é a excisão cirúrgica, e nos casos de primeiro arco deve-se ter cuidado com o nervo facial (Alternativa C).

4. No diagnóstico do cisto tireoglosso deve-se certificar que existe tireóide tópica. É certo afirmar que em caso de dúvida na USG, podese utilizar a punção aspirativa (Alternativa D).

5. Em relação ao tratamento do cisto tireoglosso é incorreto afirmar que a associação a carcinoma papilífero é de fácil diagnóstico préoperatório(Alternativa C). 